\title{
Effects of Organizational Identification on Organizational Phase and Relative Deprivation of Beauticians
}

Yun-Kyung Lim, Eunjun Park ${ }^{*}$

Department of Beauty Arts, Seokyeong University, Seoul, Korea

\author{
"Corresponding author: Eunjun Park, \\ Department of Beauty Arts, Seokyeong \\ University, 124 Seogyeong-ro, Seongbuk-gu, \\ Seoul 02713, Korea \\ Tel.: +82 29407853 \\ Email: aymdream@hanmail.net
}

Received March 1, 2017

Revised April 18, 2017

Accepted April 27, 2017

Published June 30, 2017

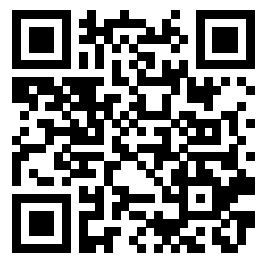

\begin{abstract}
Purpose: This study aimed to identify the impact of organizational identification on organizational phase and relative deprivation of beauticians. Methods: Data from Seoul and Gyeonggi, were collected through a survey targeting beauticians in the field; these data were then analyzed by Statistical Package for the Social Sciences (SPSS) 22.0. Results: The results revealed that there was a significant correlation between the variables of organizational identification, organizational phase, and relative deprivation. It was found that the organizational identification had significant impacts on the organizational phase and relative deprivation. Conclusion: Per the present findings, first, beauty companies are showing awareness of active participation in the government and society at the level of ethical management to improve credibility and public awareness, customer experience, and corporate image through market-oriented strategic management. This will require effort to be managed successfully. Second, the executives and managers must make this effort for smooth accomplishment of inter-organizational communication. Third, a differentiation system should be introduced to increase social identification and to reduce relative deprivation. If we create a system that can only be acquired within one organization, whether that is a diploma, overseas training, business support, or anything else, and if it differentiates our organization from others, it will promote our group's feeling special, organizational phase will increase, and relative deprivation will be reduced.
\end{abstract}

Keywords: Beauticians, Organization, Identification, Organizational phase, Relative deprivation

\section{Introduction}

현대사회는 정보화, 세계화, 글로벌화를 이루며 급변하고 있으 며, 경쟁사회에서 살아남기 위해서는 모방이 힘든 무형자원이 그 중요성을 인정받고 있는 추세이다. 대표적인 무형자원으로는 인적 자원을 들 수 있으며, 인적자원은 높은 가치를 인정받고 있다(Song $\& \mathrm{Kim}, 2011)$. 이러한 인적자원을 토대로 성장한 대표적인 사업인 미용서비스업은 심리적 의존도가 높은 사업으로 꾸준히 성장해 왔 으며, 타 기업의 조직과는 다른 집약적 기술을 필요로 하는 조직으 로 유기적 협력관계를 통하여 서비스를 제공한다.

현대의 미용서비스 조직은 과거와는 달리 유대감이 돈독하고 서 로 정보를 공유하는 등 상호작용이 활발히 이루어지고 있으며, 상 호작용이 활발한 경우가 그렇지 않을 때보다 더욱 좋은 성과를 낼 수 있다. 즉, 조직 내 커뮤니케이션이 조직의 효율성을 결정하게 되
므로 미용서비스업을 성장시키고 성과를 극대화하기 위해서는 긍 정적인 조직 문화 형성이 무엇보다 중요하다(Albert et al., 2000). 긍정적인 조직 문화 형성을 위해서는 조직에 대한 소속감과 조직 에 대한 의미부여, 관련성 등이 중요한데 이는 조직에 속해있는 개 인에 대한 활동 즉, 조직 동일시가 중요한 역할을 한다(Chung \& Nam, 2008),

조직 동일시는 구성원간의 실제적인 상호작용 없이도 형성될 수 있는 인지적, 지각적 개념이고 조직과 개인이 순기능 역할을 하는 것으로 보고되고 있으며(Mael \& Ashforth, 1992), 개인에게 자연 발생적으로 생겨 조직을 확장된 자기정체성으로 간주하게 되고 결 국 조직의 성공이라는 동일성 지각은 지속적으로 구성원들의 조직 에 대한 기여감을 갖도록 해준다. 이를 통해서 내가 속한 조직구성 원들이 사회적으로 가치 있다고 평가 받는 조직에 소속됨으로써 자 긍심을 높이게 되어 조직 안에서 조직원의 명성이나 자아 존중감이 
높아져 위상을 서게 한다(Kwon \& Kim, 2012).

조직에 소속되어 있는 개인은 자신과 조직이 분리될 수 없는 하 나라는 동일성을 인식하기도 하지만 부정적인 영향으로 인해 이질 성을 느끼기도 한다. 다른 조직과의 비교를 통한 성취의 수준이 저 하되어 상대적 박탈을 느끼게 되면 조직 문화 형성에 부정적인 영 향을 준다. 즉, 올바른 조직 문화를 위해 필요한 조직 동일시는 긍 정적인 측면에서 조직위상을 높이기도 하지만, 부정적인 측면에서 자아감 상실로 인한 상대적 박탈감을 주기도 하는 것이다.

기업에 있어서 조직은 매우 중요한 변수로서 연구되고 있다. 선 행 연구를 살펴보면 Chung \& Nam (2008)은 구성원의 조직 동일 시가 직무만족과 조직몰입에 긍정적인 영향을 미친다는 결과를 도 출하여 구성원들의 자부심과 자긍심을 높일 수 있는 조직 개념의 중요요소로 꼽았고, Jung \& Park (2007)은 조직위상이 조직 동일 시의 주요한 선행 요인임을 실증하여 조직위상이 조직구성원들을 바람직한 방향으로 이끌어 줌을 확인하였으며, 지역 기자와 지역 신문 기자를 비교 연구하여 상대적 박탈을 중요한 변수로 강조하 였다. Rhee \& Kang (2009)은 상대적 박탈감이 유발되면 지역사 회 정체성과 팀 정체성이 강화된다는 것을 실험연구를 통해 밝혀 내어 소속감 강조와 정체성 통합에 유리하다고 하였다. Jang et al. (2014)은 조직 동일시가 조직 내 의사소통과 구성원 상호작용에 긍 정적인 효과가 있는 것을 확인하였다.

또한 Dutton et al. (1994)은 긍정적인 조직위상은 조직구성원 의 자기 고양 욕구를 만족시켜주며, 사회적 자원으로써의 역할 뿐 아니라 선의와 자신감을 증진시켜주는 기능을 한다고 하였으며, Ashforth \& Mael (1989)은 조직 동일시가 인지된 조직의 위상과 관 련이 있음을 실증적인 연구를 통해 제시하여, 개인은 공식적인 것 이 아니라도 승자와 동일시하려는 경향이 있으며, 조직 안에서 이 러한 현상은 조직원들이 조직 안의 선두그룹에 동조하려는 현상으 로 나타나기도 하며, 조직을 확장된 자기로 간주함으로써 조직 성 취에 대해 대리적으로 자기 성취감을 맛볼 수 있는 등 조직과 개인 에게 순기능적 역할을 하는 특징이 있다고 하였다.

이렇듯 조직에 관한 연구는 매우 중요한 주제로 다루어지고 있 지만, 경쟁 사회의 발달과 함께 고부가가치 산업으로 급부상한 서 비스 기업 중 하나인 미용서비스에 관한 연구는 미비한 실정으로 연구의 필요성이 제기된다. 미용서비스는 전문적인 서비스 분야에 서 변화하는 기술과 지식, 정보의 증가에 맞추어 현대인들의 아름 다움에 대한 욕구를 충족시키는 중요한 역할을 하고 있다. 따라서
뒤늦게 기업화, 조직화에 합류하여 꾸준히 성장하고 있는 미용종사 자의 조직개념에 대한 구체적인 연구가 필요하다고 사료된다.

이에 본 연구에서는 미용종사자를 대상으로 하여 조직 동일시, 조 직위상, 상대적 박탈감에 대해 알아보고자 하였으며, 본 연구에서는 조직 동일시를 조직위상의 상위 개념으로 보고(Tajfel, 1982), 조직 동 일시를 독립변수로, 조직위상과 상대적 박탈감을 종속변수로 하여 미 용종사자의 조직 동일시가 조직위상과 상대적 박탈감에 어떠한 영향 을 미치는지 살펴봄으로써 미용서비스업의 종사자 개인의 정체성을 인지적, 심리적으로 동일시 할 수 있는 중요성을 강조하고 미용서비 스업의 올바른 조직 문화 활동과 정착에 도움이 되고 인적자원관리에 필요한 정보와 학문적 자료를 제공하는데 그 목적이 있다.

\section{Methods}

\section{1. 연구대상 및 자료수집}

본 연구의 조사대상은 서울과 경기도 지역의 미용종사자를 대상 으로 설정하였다. 자료의 수집방법으로 자기기입식 설문지법이 사 용되었으며, 예비조사와 본 조사를 통해 연구문제를 해결하는데 필 요한 자료가 수집되었다. 2016년 5월 1일부터 5월 15일까지 총 20 부의 예비조사를 통해 측정도구인 설문지의 구성과 내용을 수정 및 보완한 후 본 조사를 실시하였다. 본 조사는 2016년 6월 16일부터 2016년 6월 30일까지 실시되었고 총 500부의 설문지를 배포하여 수거된 480부의 설문지 중 분석에 사용되기 불충분하다고 판단되 는 9 부의 설문지를 제외한 471 부가 최종 분석 자료로 사용되었다.

\section{2. 측정항목 및 내용}

본 연구는 자료의 수집을 위해 설문지법이 사용되었다. 설문 문 항은 크게 일반적 특성, 조직 동일시, 조직위상, 상대적 박탈감의 25 문항으로 구성되었으며, 본 연구에서는 ' 1 :전혀 그렇지 않다'에 서 '5:매우 그렇다'까지의 5점 리커트 척도가 사용되었다. 설문지 의 구체적인 내용은 Table 1 과 같다.

\section{3. 분석방법}

수집한 자료를 분석하여 연구문제를 검정하기 위해 SPSS 22.0 (IBM, USA)이 사용되었고, 자료의 분석방법은 연구문제에 맞게 순 차적으로 적용되었으며 다음과 같다. 첫째, 조사대상의 일반적 특

Table 1. Configuration of the questionnaire

\begin{tabular}{lll}
\hline Research variable & Scale (No. of questions) & Quotation \& applied data \\
General characteristics & Nominal scale (6) & Organization of researchers \\
Organizational identification & 5-point Likert scale (9) & Ashforth \& Mael (1989), Ha \& Yang (2012), Lee et al. (2013), Tolman (1943) \\
Organizational phase & 5-point Likert scale (7) & Cha (2004), Dutton \& Dukerich (1991), Kwon \& Kim (2012) \\
Relative deprivation & 5-point Likert scale (3) & Allen \& Meyer (1990), Chae \& Kim (2004), Folger (2014), Kim \& Choi (2016), Rhee \& Kang (2009) \\
\hline
\end{tabular}


성을 알아보기 위해 빈도분석을 하였다. 둘째, 조직 동일시, 조직위 상, 상대적 박탈감의 차원을 알아보기 위해 요인분석과 신뢰도분 석을 하였다. 요인의 추출방법으로 주성분분석법이 사용되었고, 요인의 회전방법으로는 Varimax가 사용되었다. 셋째, 각 변수들 간의 상관관계를 검증하기 위해 상관분석을 하였다. 넷째, 조직 동 일시가 조직위상과 상대적 박탈감에 미치는 영향을 알아보기 위 해 다중회귀분석을 하였다. 독립변수의 투입방법으로 입력 방법 이 사용되었다.

\section{Results and Discussion}

\section{1. 조사대상의 일반적 특성}

조사대상인 미용종사자의 일반적 특성을 알아보기 위해 빈도분 석을 실시한 결과는 다음 Table 2 와 같다. 성별은 남성 $42.9 \%$, 여성 $57.1 \%$ 로 여성이 높게 나타났고, 연령은 20대 $23.8 \%, 30$ 대 $39.3 \%$, 40 대 $22.3 \%, 50$ 대 $14.6 \%$ 로 30 대가 가장 높게 나타났다. 학력의 경
우 고졸 이하 $21.8 \%$, 전문대(재학생포함) $30.2 \%$, 대학교(재학생포 함) $31.8 \%$, 대학원 이상(재학생포함) $16.2 \%$ 로 대학교(재학생포함) 가 가장 높게 나타났다. 총 경력을 알아본 결과 1 년 미만 $18.5 \%, 1$ 년에서 5 년 미만 $36.9 \%, 5$ 년에서 10 년 미만 $31.4 \%, 10$ 년 이상 $13.2 \%$ 로 1 년에서 5 년 미만이 가장 높게 나타났다. 현 직장의 직 원 수는 5명 미만 8.9\%, 5명에서 10명 미만 38.9\%, 10명에서 15 명 미만 $27.4 \%, 15$ 명에서 20 명 미만 $12.7 \%, 20$ 명 이상 $12.1 \%$ 로 5 명에서 10 명 미만이 가장 높게 나타났다. 월 평균 수입을 알아 본 결과 100 만원 미만 $20.5 \%, 100$ 만원에서 200 만원 미만 $24.2 \%$, 200 만원에서 300 만원 미만 $32.2 \%, 300$ 만원에서 400만원 미만 $13.4 \%, 400$ 만원 이상 $9.7 \%$ 로 200 만원에서 300 만원 미만이 가장 높게 나타났다.

\section{2. 조직 동일시, 조직위상, 상대적 박탈감의 신뢰도 및 타당도}

조직 동일시, 조직위상, 상대적 박탈감 문항에 대한 타당성 및 신뢰도 검증을 위해 요인분석과 신뢰도분석을 실시한 결과 5 가지 요인이 추출되었다. 전체 설명력은 $71.0 \%$ 로 나타났고, 일반적으로

Table 2. General characteristics

\begin{tabular}{|c|c|c|c|}
\hline Item & & Frequency $(\mathrm{N})$ & Percentage $(\%)$ \\
\hline \multirow{2}{*}{ Gender } & Men & 202 & 42.9 \\
\hline & Women & 269 & 57.1 \\
\hline \multirow{4}{*}{ Age } & $20 \mathrm{~s}$ & 112 & 23.8 \\
\hline & $30 \mathrm{~s}$ & 185 & 39.3 \\
\hline & $40 \mathrm{~s}$ & 105 & 22.3 \\
\hline & $50 \mathrm{~s}$ & 69 & 14.6 \\
\hline \multirow{4}{*}{ Education } & Below high school graduation & 103 & 21.8 \\
\hline & College degree (including enrolled students) & 142 & 30.2 \\
\hline & University degree (including enrolled students) & 150 & 31.8 \\
\hline & More than graduate-level degree (including enrolled students) & 76 & 16.2 \\
\hline \multirow{4}{*}{ Career } & Less than 1 year & 87 & 18.5 \\
\hline & 1 year to less than 5 years & 174 & 36.9 \\
\hline & 5 years to less than 10 years & 148 & 31.4 \\
\hline & More than 10 years & 62 & 13.2 \\
\hline \multirow{5}{*}{ Number of employees } & Less than 5 & 42 & 8.9 \\
\hline & 5 to less than 10 & 183 & 38.9 \\
\hline & 10 to less than 15 & 129 & 27.4 \\
\hline & 15 to less than 20 & 60 & 12.7 \\
\hline & More than 20 & 57 & 12.1 \\
\hline \multirow{6}{*}{ Monthly allowance } & Less than 1 million won & 97 & 20.5 \\
\hline & From 1 million to less than 2 million won & 114 & 24.2 \\
\hline & From 2 million to less than 3 million won & 151 & 32.2 \\
\hline & From 3 million to less than 4 million won & 63 & 13.4 \\
\hline & More than 4 million won & 46 & 9.7 \\
\hline & Total & 471 & 100.0 \\
\hline
\end{tabular}


사용되는 고유값은 1.0 이상, 요인적재치와 공통성은 0.4 이상으로 하고 각 요인을 구성하는 문항들을 토대로 하여 다음 Table 3 과 같 이 요인을 명명하였다.

\section{3. 각 변수들의 상관관계 검증}

다음 Table 4는 각 변수 간 상관관계를 알아보기 위하여 상관관 계 검증을 실시한 결과이다. 분석결과 조직 동일시(organizational identification, $\mathrm{OI}$ )의 하위요인인 개인적 동일시(personal identification, PI), 사회적 동일시(social identification, SI) 요인 은 조직위상(organizational phase, $\mathrm{OP}$ ), 상대적 박탈감(relative deprivation, $\mathrm{RD}$ ) 요인과 통계적으로 유의미한 상관관계가 있 는 것으로 나타났고, 조직위상의 하위요인인 사회적 위상(social status, SS), 개인적 위상(personal status, PS) 요인도 조직 동일 시, 상대적 박탈감 요인과 부분적으로 통계적으로 유의미한 상관

\section{Table 3. Validity and reliability test}

\begin{tabular}{|c|c|c|c|c|c|c|c|c|}
\hline \multirow{2}{*}{ Variable } & \multirow{2}{*}{ Questions } & \multicolumn{7}{|c|}{ Ingredient } \\
\hline & & $\mathrm{PI}$ & $\mathrm{SI}$ & SS & PS & $\mathrm{RD}$ & $\mathrm{CN}$ & Cronbach' $\alpha$ \\
\hline \multirow{9}{*}{ Ol } & $\begin{array}{l}\text { If I was quoted in the mass media } \\
\text { condemning a hairdresser, I would be } \\
\text { embarrassed in criticizing someone. }\end{array}$ & 0.838 & -0.095 & 0.219 & 0.026 & -0.177 & 0.627 & \multirow{5}{*}{0.874} \\
\hline & $\begin{array}{l}\text { I think I would be personally insulted } \\
\text { if others accused me of being a } \\
\text { hairdresser. }\end{array}$ & 0.836 & -0.147 & 0.170 & 0.015 & -0.001 & 0.700 & \\
\hline & $\begin{array}{l}\text { I feel that I have received personal } \\
\text { appreciation if someone praises a } \\
\text { hairdresser. }\end{array}$ & 0.835 & -0.044 & 0.101 & 0.168 & 0.025 & 0.711 & \\
\hline & $\begin{array}{l}\text { I am interested in how others evaluate } \\
\text { my work. }\end{array}$ & 0.764 & -0.047 & 0.229 & 0.056 & -0.082 & 0.729 & \\
\hline & $\begin{array}{l}\text { I think that a cosmetics-related } \\
\text { profession fits my values well. }\end{array}$ & 0.711 & -0.071 & 0.143 & 0.010 & -0.042 & 0.688 & \\
\hline & $\begin{array}{l}\text { I participate actively in meetings of } \\
\text { beauticians. }\end{array}$ & -0.123 & 0.825 & 0.089 & 0.147 & 0.061 & 0.763 & \multirow{4}{*}{0.835} \\
\hline & $\begin{array}{l}\text { When I discuss my work or beauty- } \\
\text { related work, I always use the word 'we'. }\end{array}$ & -0.080 & 0.824 & -0.007 & 0.105 & 0.058 & 0.756 & \\
\hline & $\begin{array}{l}\text { I feel a sense of belonging as a } \\
\text { beautician. }\end{array}$ & -0.020 & 0.794 & 0.252 & 0.124 & 0.042 & 0.738 & \\
\hline & $\begin{array}{l}\text { I feel a sense of solidarity and affinity } \\
\text { with other beauticians. }\end{array}$ & -0.118 & 0.681 & 0.162 & 0.309 & 0.168 & 0.791 & \\
\hline \multirow{7}{*}{ OP } & $\begin{array}{l}\text { I believe that the status of the beauty } \\
\text { industry is high compared with other } \\
\text { industries. }\end{array}$ & 0.217 & 0.191 & 0.834 & 0.156 & 0.066 & 0.750 & \multirow{4}{*}{0.790} \\
\hline & $\begin{array}{l}\text { If I were to select a job from a higher } \\
\text { authority or another organization, } \\
\text { I think I would prefer to be a hairdresser. }\end{array}$ & 0.288 & 0.182 & 0.763 & 0.168 & 0.086 & 0.649 & \\
\hline & $\begin{array}{l}\text { I believe that society appreciates } \\
\text { beauticians. }\end{array}$ & 0.247 & 0.076 & 0.689 & 0.192 & -0.013 & 0.537 & \\
\hline & $\begin{array}{l}\text { I think that beauticians have a good } \\
\text { reputation in the community. }\end{array}$ & 0.188 & 0.036 & 0.652 & 0.236 & 0.347 & 0.734 & \\
\hline & $\begin{array}{l}\text { The beauty industry is ideal for a } \\
\text { lifelong career. }\end{array}$ & 0.175 & 0.076 & 0.125 & 0.843 & -0.011 & 0.808 & \multirow{3}{*}{0.793} \\
\hline & $\begin{array}{l}\text { Even when I have enough money, } \\
\text { I will continue my cosmetics business. }\end{array}$ & -0.010 & 0.270 & 0.297 & 0.770 & -0.051 & 0.657 & \\
\hline & $\begin{array}{l}\text { I am proud of my family or children } \\
\text { becoming beauticians. }\end{array}$ & 0.094 & 0.363 & 0.117 & 0.721 & 0.118 & 0.766 & \\
\hline \multirow{3}{*}{$\mathrm{RD}$} & $\begin{array}{l}\text { I think that beauticians are more likely } \\
\text { to leave their work than others. }\end{array}$ & 0.154 & 0.031 & -0.122 & 0.029 & 0.852 & 0.680 & \multirow{3}{*}{0.714} \\
\hline & $\begin{array}{l}\text { I think that beauticians are treated } \\
\text { lower than workers in other industries. }\end{array}$ & -0.140 & 0.085 & 0.271 & -0.112 & 0.753 & 0.621 & \\
\hline & $\begin{array}{l}\text { I think that beauticians experience } \\
\text { more relative deprivation compared } \\
\text { with people from other industries. }\end{array}$ & -0.232 & 0.149 & 0.014 & 0.123 & 0.752 & 0.573 & \\
\hline \multicolumn{2}{|c|}{ Eigen value } & 3.045 & 2.803 & 2.155 & 2.116 & 1.963 & & \\
\hline \multirow{2}{*}{\multicolumn{2}{|c|}{$\begin{array}{l}\text { Description variant }(\%) \\
\text { Cumulative variance }(\%)\end{array}$}} & 17.914 & 16.490 & 12.678 & 12.449 & 11.548 & & \\
\hline & & 17.914 & 34.404 & 47.081 & 59.530 & 71.078 & & \\
\hline
\end{tabular}

Ol, organizational identification; OP, organizational phase; RD, relative deprivation; PI, personal identification; SI, social identification; SS, social status; PS, personal status; CN, commonality. 
관계가 있는 것으로 나타났다. 또한 상대적 박탈감 요인도 조직 동 일시, 조직위상 요인과 부분적으로 통계적으로 유의미한 상관관계 가 있는 것으로 나타났다.

\section{4. 조직 동일시가 조직위상에 미치는 영향}

조직 동일시(OI)의 하위요인인 개인적 동일시 $(\mathrm{PI})$, 사회적 동일 시(SI) 요인이 조직위상 $(\mathrm{OP})$ 의 하위요인인 사회적 위상(SS), 개인 적 위상(PS)에 미치는 영향에 대한 회귀분석 결과는 Table 5 와 같 다. 사회적 위상에 개인적 동일시와 사회적 동일시가 유의미하게 영향을 미치는 것으로 나타났고 개인적 동일시와 사회적 동일시가 사회적 위상 요인을 예측하는데 $23.1 \%$ 의 설명력을 갖는 것으로 나 타났다. 독립변수의 영향력을 살펴보면 개인적 동일시가 유의미하 게 $(p<0.001)$ 부(-)적으로 영향을 미치는 것으로 나타났고, 사회적 동일시가 유의미하게 $(p<0.001)$ 정 $(+)$ 적으로 영향을 미치는 것으로 나타났다. 이는 개인적 동일시가 낮아질수록 사회적 위상은 높아 지고, 사회적 동일시가 높아질수록 사회적 위상도 높아지고 있음을 의미한다. 변수의 영향력은 사회적 동일시 $\beta=0.337$, 개인적 동일시 $\beta=-0.312$ 순으로 나타났다. Variance inflation factor (VIF)는 개 인적 동일시, 사회적 동일시 모두 1.293 으로 1 에서 2 사이의 값을 나 타내고 있어 다중공선성에는 문제가 없는 것으로 나타났다.

개인적 위상에 사회적 동일시가 유의미하게 영향을 미치는 것 으로 나타났고 사회적 동일시가 개인적 위상 요인을 예측하는데 $21.4 \%$ 의 설명력을 갖는 것으로 나타났다. 독립변수의 영향력을 살 펴보면 사회적 동일시가 유의미하게 $(p<0.001)$ 정 $(+)$ 적으로 영향을 미치는 것으로 나타났다. 이는 사회적 동일시가 높아질수록 개인적 위상도 높아지고 있음을 의미한다. 변수의 영향력은 사회적 동일시 $\beta=0.389$ 크기의 영향을 미치는 것으로 나타났다. 하지만 개인적 동일시 요인은 개인적 위상에 유의미한 영향을 미치지 않았다. VIF 는 개인적 동일시, 사회적 동일시 모두 1.293 으로 1 에서 2 사이의 값 을 나타내고 있어 다중공선성에는 문제가 없는 것으로 나타났다.

이러한 결과로 보아 조직과 동일시하고 있다 하더라도 그것이 개인적인 감정일 경우 사회적 위상에 부정적인 영향을 미치게 되지 만, 소속감과 자긍심 또는 그러한 소속감을 행동으로 옮길 때 비로 소 조직위상에 긍정적 영향을 미치게 되는 것으로 사료된다. Kwon
$\& \operatorname{Kim}$ (2012)의 무용단을 대상으로 한 연구에서 독립변인으로 무 용단의 독특성, 위상, 존재로 분류하고 종속변인인 조직 동일시에 미치는 영향에 대한 분석 결과 유의한 영향을 미치는 것으로 나타났 다. 이는 독립변인을 조직 동일시로 하고 종속변인을 조직위상으로 하여 연구한 본 연구와는 변인관계가 다르지만 두 변수 사이의 영향 관계가 있는 것으로 나타나 조직 동일시와 조직위상은 서로 영향관계 가 있음을 알 수가 있다.

\section{5. 조직 동일시가 상대적 박탈감에 미치는 영향}

조직 동일시(OI)의 하위요인인 개인적 동일시(PI)와 사회적 동일 시(SI) 요인이 상대적 박탈감(RD)에 미치는 영향에 대한 회귀분석 결과는 Table 6과 같다. 상대적 박탈감에 개인적 동일시가 유의미 하게 영향을 미치는 것으로 나타났고 개인적 동일시가 상대적 박탈감 요인을 예측하는데 $13.4 \%$ 의 설명력을 갖는 것으로 나타났다. 독립변 수의 영향력을 살펴보면 개인적 동일시 유의미하게 $(p<0.001)$ 정(+)적 으로 영향을 미치는 것으로 나타나 개인적 동일시가 높아질수록 상대 적 박탈감도 높아지고 있음을 의미한다. 변수의 영향력은 개인적 동 일시 $\beta=0.250$ 크기의 영향을 미치는 것으로 나타났다. 하지만 사회적 동일시 요인은 상대적 박탈감에 유의미한 영향을 미치지 않았다. VIF 는 개인적 동일시, 사회적 동일시 모두 1.293 으로 1 에서 2 사이의 값을 나타내고 있어 다중공선성에는 문제가 없는 것으로 나타났다.

이러한 결과는 조직과 동일시하고 있어도 단순히 타인이 우리조 직을 나쁘게 말하면 기분이 나쁘다거나, 칭찬을 하면 기분이 좋다 거나 하면 상대적 박탈감은 더 높아지고 있음을 보여주고 있다. 그 러나 내가 아닌 ‘우리' 라고 생각하고 조직에 소속되어 있다는 확신 을 가지고 있거나 그러한 행동을 하고 있을 때는 상대적 박탈감은 줄어드는 것을 확인 할 수 있었다. Kim \& Choi (2016)의 호텔 비 정규직을 대상으로 상대적 박탈감이 직업 정체성과 고객 지향성 에 미치는 영향에 관한 연구에서 조직 동일시 변수를 감정이입, 개 인-직업 부합, 일체감으로 도출하여 상대적 박탈감이 감정이입, 개인-직업 부합, 일체감에 부분적으로 유의한 영향을 미치는 것을 확인하였다. 개인-직업 부합은 본 연구의 조직 동일시에서 개인적 동일시와 사회적 동일시와 유사한 성격을 띠고 있어서 본 연구를 지지하고 있다. 또한, Rhee \& Kang (2009)의 연구에서도 상대적

\section{Table 4. Proven correlation of variables}

\begin{tabular}{|c|c|c|c|c|c|c|}
\hline \multirow{2}{*}{\multicolumn{2}{|c|}{ Variable }} & \multicolumn{2}{|c|}{$\mathrm{OI}$} & \multicolumn{2}{|c|}{ OP } & \multirow{2}{*}{$\mathrm{RD}$} \\
\hline & & $\mathrm{PI}$ & $\mathrm{SI}$ & SS & PS & \\
\hline \multirow{2}{*}{ Ol } & $\mathrm{PI}$ & 1 & & & & \\
\hline & $\mathrm{SI}$ & $0.476^{* *}$ & 1 & & & \\
\hline \multirow{2}{*}{$\mathrm{OP}$} & SS & $-0.158^{*}$ & $0.189^{*}$ & 1 & & \\
\hline & PS & $0.312^{* *}$ & $0.452^{* *}$ & $0.458^{* *}$ & 1 & \\
\hline $\mathrm{RD}$ & & $0.231^{* *}$ & $0.177^{*}$ & -0.143 & $0.106^{* *}$ & 1 \\
\hline
\end{tabular}

OI, organizational identification; OP, organizational phase; PI, personal identification; SI, social identification; SS, social status; PS, personal status; RD, relative deprivation; ${ }^{*} p<0.05 ;{ }^{* *} p<0.01$. 
박탈감에 대해 연구하여 지역사회 정체성과 팀 정체성이 상대적 박 탈감에 유의한 영향관계에 있음을 확인하여 소속감과 소속감을 느 끼게 하는 행동이 개인적 동일시와 사회적 동일시와 유사한 성격을 띠고 있어서 상대적 박탈감에 중요한 요인임을 알 수 있다.

\section{Conclusion}

본 연구는 미용종사자의 조직 동일시가 조직위상과 상대적 박탈 감에 미치는 영향을 알아보는 것을 목적으로 하였다. 서울, 경기 지 역의 미용종사자를 대상으로 설문지법을 통해 수집된 자료 471 부 는 SPSS 22.0 을 통해 분석되었고 적용된 분석방법은 빈도분석, 요 인분석, 신뢰도분석, 상관분석, 회귀분석이었다.

연구결과는 다음과 같았다. 첫째, 조사대상의 일반적 특성을 알 아보기 위해 빈도분석을 실시한 결과 성별은 여성이 높았고, 연령 은 30 대가 높게 나타났다. 학력은 대학교(재학생포함)이 가장 높게 나타났다. 총 경력은 1 년에서 5 년 미만이 가장 높게 나타났고, 현 직장의 직원 수는 5 명에서 10 명 미만이 가장 높았으며, 월 평균 수 입은 200 만원에서 300 만원 미만이 가장 높게 나타났다. 둘째, 조 직 동일시, 조직위상, 상대적 박탈감을 요인분석한 결과, 조직 동일 시는 사회적 동일시, 개인적 동일시의 두 가지 요인이 도출되었고, 조직위상은 사회적 위상, 개인적 위상의 두 가지 요인이 도출되었 으며, 상대적 박탈감은 단일차원으로 구성되었다. 셋째, 조직 동일 시, 조직위상, 상대적 박탈감 각 변수들의 상관관계를 검증한 결과 통계적으로 유의미한 상관관계가 있는 것으로 나타났다. 넷째, 조 직 동일시가 조직위상의 하위요인인 사회적 위상과 개인적 위상에 미치는 영향을 알아본 결과, 부분적으로 유의한 영향을 미치는 것
으로 나타났고 개인적 동일시는 개인적 위상에 유의한 영향을 미치 지 않았다. 다섯째, 조직 동일시의 하위요인인 개인적 동일시는 상대 적 박탈감에 미치는 영향을 미치는 것으로 나타났고, 사회적 동일시 는 상대적 박탈감에 유의한 영향을 미치지 않는 것으로 나타났다.

이렇듯 미용종사자의 조직 동일시가 조직위상과 상대적 박탈감 에 유의한 영향을 미치는 중요한 변수임을 확인하였으며 본 연구의 결과에 따른 시사점으로는 첫째, 개인적 동일시와 사회적 위상은 부의 관계, 사회적 동일시와 사회적 위상은 정의 관계를 갖는 것을 확인할 수 있었다. 상대적 박탈감 또한 개인적 동일시와 정의 관계 를 갖는 것으로 나타났다. 이는 개인과 동일시하는 것보다 '우리'와 동일시 할 때 사회적 위상이 높아지고(Fombrun, 1996) 상대적 박 탈감이 낮아진다는 뜻으로 사회적으로 조직위상이 높은 조직일수 록 그 조직과 동일시하려는 경향이 강하게 나타나며, 그 조직에 소 속됨에 자부심을 느끼고 더욱더 몰입하려는 경향이 나타나게 된다 고 해석할 수 있다(Rousseau, 1998). 때문에 미용기업은 자사의 신 뢰도와 대외 인지도를 높이기 위하여 윤리경영 차원에서 정부와 사 회에 대한 적극적인 참여의식을 보이고, 고객관점에서는 시장지향 적인 전략적 경영을 통해 기업이미지가 성공적으로 관리될 수 있도 록 노력해야 한다. 둘째, 조직간 커뮤니케이션이 원활하게 이루어 질 수 있도록 경영자와 관리자의 노력이 요구된다. 조직구성원들에 게 적극적 조직지원과 교육훈련을 통해 조직의 목표와 비전을 공유 하게 함으로써 조직에 대한 강한 자긍심과 소속감, 그리고 심리적 인 애정을 가질 수 있도록 유도하며, 직무 외 인간적인 교류를 통해 정신적인 공감을 유지시켜 나가는 노력이 필요하다. 셋째, 사회적 동일시를 높이고 상대적 박탈감을 줄이기 위한 방안으로 차별화 제 도를 도입한다. 우리조직 내에서만 취득할 수 있는 자격증이나 수 료증, 해외연수, 사업지원 등의 제도를 만들어서 다른 조직과 차별

Table 5. Impact of organizational identification on organizational phase

\begin{tabular}{|c|c|c|c|c|c|c|c|c|c|c|}
\hline \multirow{2}{*}{$\begin{array}{l}\text { Dependent } \\
\text { variable }\end{array}$} & \multirow{2}{*}{$\begin{array}{l}\text { Independent } \\
\text { variable }\end{array}$} & \multirow{2}{*}{ B } & \multirow{2}{*}{$\beta$} & \multirow{2}{*}{$\mathrm{t}$} & \multirow{2}{*}{$\mathrm{R}^{2}$} & \multirow{2}{*}{ Modified $\mathrm{R}^{2}$} & \multicolumn{2}{|c|}{ Collinearity } & \multirow{2}{*}{$F$} & \multirow{2}{*}{$\begin{array}{l}\text { Probability of } \\
\text { significance }\end{array}$} \\
\hline & & & & & & & Tolerance & VIF & & \\
\hline \multirow{3}{*}{ SS } & (a constant) & 3.136 & & 9.407 & \multirow{3}{*}{0.231} & \multirow{3}{*}{0.224} & & & \multirow{3}{*}{9.417} & \multirow{3}{*}{$0.000^{* * *}$} \\
\hline & $\mathrm{PI}$ & -0.331 & -0.312 & $-3.577^{* * *}$ & & & 0.773 & 1.293 & & \\
\hline & $\mathrm{SI}$ & 0.345 & 0.337 & $3.864^{* * *}$ & & & 0.773 & 1.293 & & \\
\hline \multirow{3}{*}{ PS } & (a constant) & 1.463 & & 7.616 & \multirow{3}{*}{0.217} & \multirow{3}{*}{0.214} & & & \multirow{3}{*}{63.779} & \multirow{3}{*}{$0.000^{* * *}$} \\
\hline & $\mathrm{PI}$ & 0.149 & 0.131 & 2.798 & & & 0.773 & 1.293 & & \\
\hline & $\mathrm{SI}$ & 0.426 & 0.389 & $8.288^{* * *}$ & & & 0.773 & 1.293 & & \\
\hline
\end{tabular}

B, unstandardized coefficient; $\beta$, standardized coefficient; t, t-value; $\mathrm{R}^{2}$, correlation coefficient; Modified $\mathrm{R}^{2}$, modified correlation coefficient; VIF, variance inflation factor; $F, F$-value; SS, social status; PI, personal identification; SI, social identification; PS, personal status; ${ }^{* * *} p<0.001$.

Table 6. Impact of organizational identification on relative deprivation

\begin{tabular}{|c|c|c|c|c|c|c|c|c|c|c|}
\hline \multirow{2}{*}{$\begin{array}{l}\text { Dependent } \\
\text { variable }\end{array}$} & \multirow{2}{*}{$\begin{array}{l}\text { Independent } \\
\text { variable }\end{array}$} & \multirow{2}{*}{ B } & \multirow{2}{*}{$\beta$} & \multirow{2}{*}{$\mathrm{t}$} & \multirow{2}{*}{$\mathrm{R}^{2}$} & \multirow{2}{*}{ Modified $\mathrm{R}^{2}$} & \multicolumn{2}{|c|}{ Collinearity } & \multirow{2}{*}{$F$} & \multirow{2}{*}{$\begin{array}{l}\text { Probability of } \\
\text { significance }\end{array}$} \\
\hline & & & & & & & Tolerance & VIF & & \\
\hline \multirow{3}{*}{ RD } & (a constant) & 2.758 & & 15.015 & & & & & & \\
\hline & $\mathrm{Pl}$ & 0.247 & 0.250 & $4.844^{* * *}$ & 0.139 & 0.134 & 0.773 & 1.293 & 13.169 & $0.000^{* * *}$ \\
\hline & $\mathrm{SI}$ & -0.040 & -0.042 & -0.818 & & & 0.773 & 1.293 & & \\
\hline
\end{tabular}

$\mathrm{B}$, unstandardized coefficient; $\beta$, standardized coefficient; $\mathrm{t}$, t-value; $\mathrm{R}^{2}$, correlation coefficient; Modified $\mathrm{R}^{2}$, modified correlation coefficient; VIF, variance inflation factor; $F, F$-value; RD, relative deprivation; PI, personal identification; SI, social identification; ${ }^{* * *} p<0.001$. 
성을 두어 내가 소속한 집단이 더욱 특별하게 느껴지도록 돕는다. 조직결속력이 강해질수록 '우리' 라는 소속감이 강해지고 행동으로 움직일 때 조직위상은 높아지고 상대적 박탈감은 줄어들 것이다.

본 연구는 미용종사자를 대상으로 조직 동일시가 조직위상과 상 대적 박탈감에 어떠한 영향을 미치는지 파악하여 미용종사자의 조 직 활동과 인적자원관리에 필요한 정보와 학문적 자료를 제공하고 미용 산업의 발전을 위하여 실용적인 교육이 이루어지는데 도움이 되고자 진행되었다. 본 연구에서는 일부 지역의 미용종사자를 대상 으로 표본구성을 했으므로 연구 결과를 일반화시키는데 제한점을 가질 수 있으나, 본 연구를 바탕으로 다양한 변수를 세분화하여 후 속연구가 이루어지길 기대한다.

\section{References}

Albert S, Ashforth BE, Dutton JE. Organizational identity and identification: charting new waters and building new bridges. Academy of Management Review, 25: 13-17, 2000.

Allen NJ, Meyer JP. The measurement and antecedents of affective, continuance and normative commitment to the organization. Journal of Occupational and Organizational Psychology, 63: 1-18, 1990.

Ashforth BE, Mael F. Social identity theory and the organization. Academy of Management Review, 14: 20-39, 1989.

Cha HW. A study on the development of Korean corporate reputation index. Advertising Research, 64: 259-289, 2004.

Chae JM, Kim JN. Relative deprivation and psychological adaptation of the North Korean defectors: the influence of individual identity and social identity. Korean Journal of Social and Personality Psychology, 18: 41-63, 2004.

Chung MS, Nam SH. A study on the impact of organizational identity on organizational citizenship behavior in social welfare organizations: using job satisfaction and organizational commitment as mediating variables. Korean NPO Review, 6: 39-61, 2008.

Dutton JE, Dukerich JM, Harquail CV. Organizational images and member identification. Administrative Science Quarterly, 39: 239-263, 1994.

Dutton JE, Dukerich JM. Keeping an eye on the mirror: image and identity in organizational adaptation. Academy of Management Journal, 34: 517-554, 1991.

Folger R. A referent cognitions theory of relative deprivation.
In: Relative deprivation and social comparison: the Ontario symposium, volume 4. Olson JM, Herman CP, Zanna MP (eds.), Psychology Press, New York and London, pp34-41, 2014.

Fombrun CJ. Reputation: realizing value from the corporate image. Harvard Business Publishing, Brighton, pp218222, 1996.

Ha S, Yang H. Research on a professional organization's members' social identification: focusing on the relationships of group and professional identifications with organizational identification. Korean Journal of Management, 20: 73102, 2012.

Jang SH, Roh MH, An SC, Son SY. The influence of organizational identification on knowledge sharing behavior: focusing on the mediating effect of occupational self-efficacy. Journal of Human Resource Management Research, 21: 217239, 2014.

Jung SH, Park SH. A study on online journalism and the change of news production system: in-depth interview on national and local newspaper journalists. Journal of Communication Research, 43: 37-69, 2007.

Kim SW, Choi WS. The effect of relative deprivation perceived by hotel permanent employee's on occupational identity and customer orientation. Journal of Tourism Management Research, 70: 1-22, 2016.

Kwon HI, Kim EH. The antecedents of organizational identification of dance team: professional dancers' perceived distinctiveness, prestige, and salience of rival. The Korean Journal of Dance Research, 12: 93-103, 2012.

Lee JS, Kim CS, Hor SR. The effect of identity, image of travel agencies on the organizational identification and royalty. Journal of Tourism Management Research, 57: 289-314, 2013.

Mael F, Ashforth BE. Alumni and their alma mater: a partial test of the reformulated model of organizational identification. Journal of Organizational Behavior, 13: 103-123, 1992.

Rhee YC, Kang JH. The causal effects of relative deprivation on team identification and regional identification: an experimental study. Korean Journal of Sport Management, 14: 87-103, 2009.

Rousseau DM. Why workers still identify with organizations. Journal of Organizational Behavior, 19: 217-233, 1998.

Song GR, Kim JG. The influence of strategic human resource management system on intellectual capital and 
Relation of Organizational Identification, Organizational Phase, and Relative Deprivation of Beauticians

innovative capabilities. Journal of Human Resource

Management Research, 18: 105-127, 2011.

Tajfel H. Social psychology of intergroup relations. Annual Review of Psychology, 33: 1-39, 1982.

Tolman EC. Identification and the postwar world. Journal of Abnormal and Social Psychology, 38: 141-148, 1943. 


\section{국문초록}

\section{미용종사자의 조직 동일시가 조직위상과 상대적 박탈감에 미치는 영향}

임윤경, 박은준

서경대학교 미용예술학과, 서울, 한국

목적: 본 연구는 미용종사자의 조직 동일시가 조직위상과 상대적 박탈감에 미치는 영향을 알아보는 것을 목적으로 하였다. 방법: 서울, 경기 지역의 미용종사자를 대상으로 설문지법을 통해 수집된 자료 471부는 SPSS 22.0을 통해 분석되었다. 결과: 연구결과 조직 동일시, 조직위상, 상대적 박탈감의 각 변수들은 유의미한 상관관계가 있는 것으로 나타났고, 조직 동일시가 조직위상과 상대 적 박탈감에 유의미한 영향을 미치는 것을 알 수 있었다. 결론: 본 연구 결과에 따른 시사점으로는 첫째, 미용기업은 자사의 신뢰도 와 대외 인지도를 높이기 위하여 윤리경영 차원에서 정부와 사회에 대한 적극적인 참여의식을 보이고, 고객관점에서는 시장지향적 인 전략적 경영을 통해 기업이미지가 성공적으로 관리 될 수 있도록 노력해야 한다. 둘째, 조직간 커뮤니케이션이 원활하게 이루어 질 수 있도록 경영자와 관리자의 노력이 요구된다. 셋째, 사회적 동일시를 높이고 상대적 박탈감을 줄이기 위한 방안으로 차별화 제 도를 도입해야 한다. 우리조직 내에서만 취득할 수 있는 자격증이라든지 수료증, 해외연수, 사업지원 등의 제도를 만들어서 다른 조 직과 차별성을 두어 내가 소속한 집단이 더욱 특별하게 느껴지도록 돕는다면 조직위상은 높아지고 상대적 박탈감은 줄어들 것이다.

핵심어: 미용종사자, 조직, 동일시, 조직위상, 상대적 박탈감

\section{참고문헌}

권형일, 김은혜. 무용단의 지각된 독특성, 위상, 그리고 경쟁 조직의 존재가 무용단에 대한 조직동일시에 미치는 영향. 한국무 용학회지, 12: 93-103, 2012.

김신원, 최우성. 호텔 비정규직이 지각하는 상대적 박탈감이 직업정체성과 고객지향성에 미치는 영향. 관광경영연구, 70 : 1-22, 2016.

송경렬, 김종관. 전략적 인적자원관리 시스템이 지적 자본과 혁신역량에 미치는 영향. 인적자원관리연구, 18: 105-127, 2011. 이용재, 강준호. 상대적 박탈감이 지역사회 및 스포츠팀 정체성에 미치는 영향에 관한 연구. 한국스포츠산업경영학회지, $14:$ 87-103, 2009.

이진석, 김창수, 허성란. 여행기업의 정체성 및 이미지가 조직동일시와 충성도에 미치는 영향 연구. 관광경영연구, $57: 289-$ 314, 2013.

장승훈, 노명화, 안상철, 손승연. 조직동일시가 지식공유행동에 미치는 영향: 직업적 자기효능감의 매개효과를 중심으로. 인 적자원관리연구, 21: 217-239, 2014.

정무성, 남석훈. 사회복지조직에서의 조직동일시가 조직시민행동에 미치는 영향: 직무만족과 조직몰입을 매개변인으로. 한국 비영리연구, 6: 39-61, 2008.

정승호, 박선희. 인터넷 취재로 인한 언론인의 취재활동 및 노동여건, 언론사내 조직위상의 변화: 전국지 지역기자와 지역신 문 기자 비교 분석. 언론정보연구, 43: 37-69, 2007.

차희원. 기업명성의 개념 정립과 한국형 명성지수개발에 관한 연구. 광고연구, 64: 259-289, 2004.

채정민, 김종남. 북한이탈주민의 상대적 박탈감과 심리적 적응. 한국심리학회지: 사회 및 성격, 18: 41-63, 2004.

하신영, 양혁승. 전문조직 구성원들의 사회적 동일시에 관한 연구: 그룹동일시와 직업동일시의 조직동일시와의 관계를 중심으로. 인사조직연구, 20: 73-102, 2012. 


\section{中文摘要}

\section{美容从业者的组织认同对组织阶段和相对剥夺感的影响}

任潤敬，朴銀俊 ${ }^{*}$

西京大学美容艺术学科, 首尔, 韩国

目的: 探讨美容从业者的组织认同对组织阶段和相对剥夺感的影响。方法: 在首尔、京畿道等地区工作的美容从业者为对 象进行问卷调查, 利用 SPSS 22.0 分析收集的调查资料471份。结果：组织认同，组织阶段，相对剥夺感等变数之间具有 统计意义的相互关系。组织认同对组织阶段, 相对剥夺感具有统计意义的影响。结论: 通过研究得出 : 第一, 美容企业 为提高企业的信誉和公众意识, 需应积极参与对政府和社会的道德管理, 通过以市场为导向的战略管理, 成功管理企业 形象 ; 第二, 为组织间交流顺利, 经营者和管理者必须做出努力; 第三, 为提高社会认同, 减少相对剥夺感, 需引入差 别化制度。如果只在自己所属的组织内创建资格证或证书、海外培训、业务支持等制度, 与其他组织区别, 会觉得自己 所属的组织是非常特别的, 将会提高组织阶段, 降低相对剥夺感。

关键词: 美容从业者，组织，认同，组织阶段，相对剥夺感 